\title{
Learning curves for pediatric laparoscopy: how many operations are enough? The Amsterdam experience with laparoscopic pyloromyotomy
}

\author{
M. W. N. Oomen $\cdot$ L. T. Hoekstra • \\ R. Bakx $\cdot$ H. A. Heij
}

Received: 5 May 2009/Accepted: 13 October 2009/Published online: 21 February 2010

(c) The Author(s) 2010. This article is published with open access at Springerlink.com

\begin{abstract}
Background Few studies on the surgical outcomes of open (OP) versus laparoscopic pyloromyotomy (LP) in the treatment of hypertrophic pyloric stenosis have been published. The question arises as to how many laparoscopic procedures are required for a surgeon to pass the learning curve and which technique is best in terms of postoperative complications. This study aimed to evaluate and quantify the learning curve for the laparoscopic technique at the authors' center. A second goal of this study was to evaluate the pre- and postoperative data of OP versus LP for infantile hypertrophic pyloric stenosis.

Methods A retrospective analysis was performed for 229 patients with infantile hypertrophic pyloric stenosis. Between January 2002 and September 2008, 158 infants underwent OP and 71 infants had LP.

Results The median operating time between the $\mathrm{OP}$ (33 $\mathrm{min}$ ) and LP (40 min) groups was significantly different. The median hospital stay after surgery was 3 days for the OP patients and 2 days for the LP patients $(p=0.002)$. The postoperative complication rates were not significantly different between the OP (21.5\%) and LP (21.1\%) groups $(p=0.947)$. Complications were experienced by $31.5 \%$ of the first $35 \mathrm{LP}$ patients. This rate decreased to $11.4 \%$ during the next $35 \mathrm{LP}$ procedures $(p=0.041)$. Two perforations and three conversions occurred in the first LP group, compared with one perforation in the second LP group.
\end{abstract}

M. W. N. Oomen $(\varangle) \cdot$ L. T. Hoekstra $\cdot$ R. Bakx $\cdot$ H. A. Heij Department of Pediatric Surgery, Emma Children's Hospital, Academic Medical Center, Meibergdreef 9,

1105 AZ Amsterdam, The Netherlands

e-mail: m.w.oomen@amc.uva.nl
Conclusion The number of complications decreased significantly between the first and second groups of the LP patients, with the second group of LP patients quantifying the learning curve. Not only was the complication rate lower in the second LP group, but severe complications also were decreased. This indicates that the learning curve for LP in the current series involved 35 procedures.

Keywords Hypertrophic pyloric stenosis .

Laparoscopic pyloromyotomy $\cdot$ Learning curve

A common cause of vomiting after feeding in the first few weeks of life is infantile hypertrophic pyloric stenosis (HPS). This disorder is characterized by hypertrophy and hyperplasia of the circular muscle layer of the pylorus, with stenosis of the pylorus channel causing gastric outlet obstruction, gastric distension, and retrograde peristalsis in the stomach, which can be seen by physical examination after feeding. As a consequence, dehydration and hypochloremic metabolic alkalosis will occur.

No clear pathophysiologic sequence or etiology for HPS has been described, although a relation seems to exist between maternal Bendectin use in the first trimester and infantile hypertrophic pyloric stenosis. The incidence of HPS is approximately 1-3 per 1,000 live births [1]. More often seen in boys, HPS occurs with a male-to-female ratio of $4: 1$ [2].

The surgical treatment of choice for HPS in the past century was the technique described in 1912 by Ramstedt [3], who introduced the longitudinal splitting of the seromuscular layer of the pylorus without suturing, termed "pyloromyotomy." This procedure relieves the constriction and allows normal passage of stomach contents into the duodenum. The operation traditionally has been 
performed through a classical right upper quadrant transverse incision. Although effective at providing excellent exposure of the pylorus, this method results in an abdominal scar that grows with the patient, often becoming quite significant with time.

Several other approaches currently are advocated for pyloromyotomy. In 1986, Tan and Bianchi [4] described a new technique of performing pyloromyotomy through a supraumbilical skinfold incision. This approach achieves an excellent cosmetic outcome with an apparently unscarred abdomen. In 1991, Alain et al. [5] introduced the laparoscopic approach. Since then, a few centers have reported their outcomes for open pyloromyotomy (OP) compared with laparoscopic pyloromyotomy (LP) [6-11]. The potential advantages of LP have included a shorter hospital stay, improved cosmesis, a shorter postoperative recovery, and less postoperative pain.

The question arises whether LP is a better operation technique for HPS and therefore superior to OP. Two prospective, randomized controlled trials have compared LP and OP groups undergoing hypertrophic pyloric stenosis [12, 13]. Leclair et al. [12] showed that LP has a complication rate similar to that for the open umbilical approach but may expose patients to a risk of inadequate pyloromyotomy. However, the study of St Peter et al. [13] reported the benefits of LP as less postoperative pain, reduced postoperative emesis, and fewer complications. No difference in operating time between OP and LP was observed. However, this finding is not supported by Leclair et al. [12], who showed that the operation time was longer in the laparoscopic group. Overall, the conclusions with regard to the superiority of the laparoscopic procedure are contradictory.

Another issue with regard to LP is the existence of a learning curve. As known from many laparoscopic procedures such as colonic resection, quite a number of procedures are required before the technique is safely performed. Kramer et al. [14] showed a decrease in operating time with children who underwent laparoscopic extramucosal pyloromyotomy for hypertrophic pyloric stenosis and found a positive learning curve. The first operations required an average operation time of more than $30 \mathrm{~min}$. After some years of experience with the laparoscopic approach, the operations lasted an average of $16 \mathrm{~min}$. Another study also showed a steep learning curve in laparoscopic operations, with a decrease in operating time after about 30 cases [15].

This study aimed to evaluate and quantify the learning curve for the laparoscopic technique at our center. A second goal of this study was to evaluate the pre- and postoperative data for OP versus LP for infantile hypertrophic pyloric stenosis.

\section{Patients and methods}

A retrospective study of 229 patients (196 boys and 33 girls) with infantile hypertrophic pyloric stenosis was performed. From January 2002 to September 2008, these patients underwent surgery at the Academic Medical Center and the Vrije Universiteit Medical Center in Amsterdam, the Netherlands. Of these infants, 158 (69\%) underwent a standard OP via a circumbilical incision [4], and $71(31 \%)$ had LP. The LP was introduced by one surgeon (M.O.) who had been trained during residency in another clinic. Half of the procedures were performed by this single surgeon. A total of four different surgeons performed the remaining 35 procedures, the large majority of which were supervised by the initiating surgeon.

Parents were informed about the different types of procedures and offered LP for their child if they desired this approach. It was explained that LP was a relatively new technique with unproven advantages over OP. The parents were allowed to choose the type of operation performed.

Preoperative parameters including sex, age at admission, and age at operation were collected from all the parents. The peri- and postoperative data studied in both groups were operating time, hospital stay, the number and nature of complications, and the consequences of these complications. Furthermore, the number of conversions and their indications were counted.

The data were analyzed statistically using SPSS version 14.0 (SPSS, Chicago, IL, USA) and the chi-square test. Significance was defined as a $p$ value of 0.05 or less.

\section{Preoperative care}

The diagnosis of hypertrophic pyloric stenosis was made by ultrasound or physical examination after feeding showing a peristaltic wave over the stomach. Before the operation, all the infants had correction of the hypochloremic metabolic alkalosis. All the patients were under general anesthesia. The umbilicus and the abdomen were thoroughly cleansed with chlorhexidine or iodine two times, and a sterile field was created. Prophylactic antibiotics were administered if indicated.

Surgical techniques

\section{Open pyloromyotomy}

A semicircular incision was made in the supraumbilical skinfold following the contours of the umbilicus. The skin, subcutaneous tissues, and fascia were undermined with diathermy dissection. The fascia was opened. Luxation of the stomach with the pylorus was followed by an incision 
in the serosa of the pylorus. The muscle was split down to the mucosa. The stomach was replaced intraabdominally. The linea alba was closed with Vicryl sutures, and the cutis was approximated with Monocryl. The wound was closed with Steristrips [4].

\section{Laparoscopic pyloromyotomy}

A small incision was made in the subumbilical region, through which a 5-mm trocar was introduced. A 3-mm trocar was inserted through the abdominal wall at the right upper quadrant under direct vision so the duodenum could be grasped. A disposable laparoscopic knife was introduced in the epigastric region. The avascular part of the pylorus was identified, and the serosa was incised. The knife was pulled back, and the laparoscopic spreader was used for the pyloromyotomy. The stomach was filled with air to determine whether perforations had occurred. After removal of the instruments, the incisions were closed [5].

\section{Postoperative care}

In all cases, a standard postoperative feeding regimen was started for both groups. At $6 \mathrm{~h}$ after the operation, a full feeding ad libitum regimen was administered. Discharge followed when the infant tolerated full feeding. The babies were reviewed at an outpatient follow-up visit after 2 or 3 weeks unless postoperative complications occurred.

\section{Results}

\section{Preoperative data}

The OP group consisted of 133 boys and 25 girls, and the LP group comprised 63 boys and 8 girls. The median age at the date of the operation was 4.4 weeks (range, 1.324.4 weeks $)$ in the OP group $(n=158)$ and 4.7 weeks (range, 1.7-46.3) weeks in the LP group $(n=71)$. This difference is not significant. The demographic details are shown in Table 1.

\section{Perioperative data}

The median operating times were significantly different between the OP $(33 \mathrm{~min})$ and the LP (40 min) groups $(p=0.000)$.

\section{Postoperative data}

The median hospital stay after surgery was 3 days for the OP patients and 2 days for the LP patients $(p=0.002)$.
Table 1 Main pyloromyotomy results

\begin{tabular}{|c|c|c|c|}
\hline & $\begin{array}{l}\text { Open } \\
(n=158)\end{array}$ & $\begin{array}{l}\text { Laparoscopic } \\
(n=71)\end{array}$ & $\begin{array}{l}p \\
\text { Value }\end{array}$ \\
\hline Sex ratio (M:F) & $133: 25$ & $63: 8$ & NS \\
\hline $\begin{array}{l}\text { Median age at operation: } \\
\text { weeks (range) }\end{array}$ & $\begin{array}{l}4.4(1.3- \\
24.4)\end{array}$ & $4.7(1.7-46.3)$ & NS \\
\hline Operating time $(\min )$ & 33 & 40 & 0.000 \\
\hline $\begin{array}{l}\text { Hospital stay after surgery } \\
\text { (days) }\end{array}$ & 3 & 2 & 0.002 \\
\hline Total length of stay (days) & 5 & 4 & 0.048 \\
\hline $\begin{array}{l}\text { Postoperative complication } \\
\text { rate }(\%)\end{array}$ & 21.5 & 21.1 & 0.947 \\
\hline
\end{tabular}

Table 2 Postoperative complications after open (OP) and laparoscopic (LP) pyloromyotomy

\begin{tabular}{lcl}
\hline & $\begin{array}{l}\text { OP } \\
n(\%)\end{array}$ & $\begin{array}{l}\text { LP } \\
n(\%)\end{array}$ \\
\hline No complications & $124(78.5)$ & $56(78.9)$ \\
Perforation & $2(1.3)$ & $3(4.2)$ \\
Wound infection & $9(5.7)$ & $2(2.8)$ \\
Dehiscence of fascia & $12(7.6)$ & 0 \\
Delayed passage & $2(1.3)$ & $2(2.8)$ \\
Injury to the duodenum & $2(1.3)$ & 0 \\
Gastroenteritis & $2(1.3)$ & $1(1.4)$ \\
Abscess & $3(1.9)$ & $1(1.4)$ \\
Other complications & $2(1.2)$ & $3(4.2)$ \\
Conversion to OP & & $3(4.2)$ \\
Total & 158 & 71
\end{tabular}

The median total hospital stay was 5 days for the OP group and 4 days for the LP group $(p=0.048)$.

The postoperative complication rate was not significantly different between the OP group (21.5\%) and the LP group $(21.1 \% ; p=.947)$. The postoperative complications are shown in Table 2.

The complication rate for the LP patients was analyzed in groups of 10 patients to gain information concerning the learning curve. The LP group seemed to show a trend of reduction in postoperative complications after some experience with the LP technique. The results are shown in Fig. 1.

The LP patients were split into two groups to analyze whether differences existed in complication rates and severity of complications. The first LP group consisted of the first $35 \mathrm{LP}$ patients, with the next $35 \mathrm{LP}$ patients belonging to the second group. In the first 35 LP-procedures, complications were experienced by $31.5 \%$ of the patients, whereas this rate decreased to $11.4 \%$ in the second 35 LP procedures $(p=0.041)$. Among the complications 


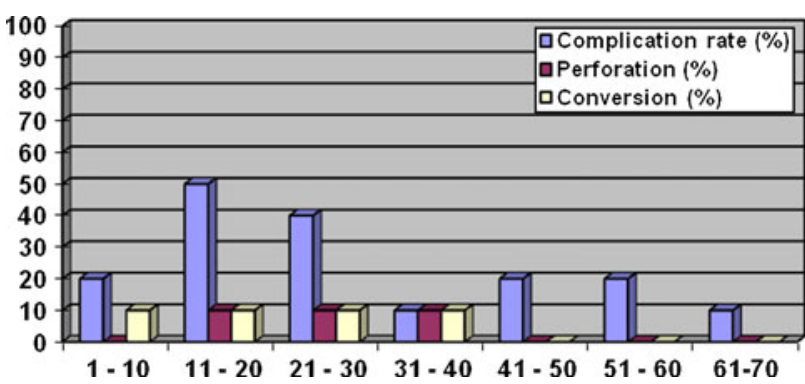

Fig. 1 Analysis of the complication rate for groups of 10 laparoscopic pyloromyotomy (LP) patients. The vertical dimension shows the percentage of patients, and the horizontal dimension shows the number of patients grouped by 10

in the first group were two perforations requiring reoperation and three conversions. In the second LP group, only one perforation was observed, which was recognized preoperatively and the procedure was converted. The median operating time was $42 \mathrm{~min}$ for the first LP group and $40 \mathrm{~min}$ for the second LP group.

\section{Discussion}

In this study, the learning curve after introduction of LP was analyzed by comparing the number of complications during the first half of the LP procedures with those during the second half of the LP procedures. This study showed a significant decrease in the number of complications between the first and second groups of LP patients. The second LP group not only had a lower complication rate but also showed a decrease in severe complications. This indicates that the learning curve for LP in our series involved 35 procedures.

To date, this series has not shown LP to be a better technique than OP in terms of postoperative complications. However, the LP group seems to show a trend toward reduction of postoperative complications after 35 procedures. Therefore, the first 35 patients might reflect the learning curve, with a reduction in complications for the last 35 patients.

A complication rate of $20 \%$ was reported for 10 laparoscopic operations performed in 2005 when we started to perform LP. The next 10 infants who underwent LP had a complication rate of $50 \%$. After some experience with the laparoscopic approach, the average was reduced to $20 \%$ and even to $10 \%$ after 70 operations. There seems to be a trend toward fewer complications, although we cannot ensure this benefit. It might be expected that the reduction in complications can be sustained and that a reduction in postoperative complications might be possible. This reduction might justify LP, but must be investigated further with a randomized controlled clinical trial.
One study in the Netherlands reported a learning curve with children who underwent laparoscopic extramucosal pyloromyotomy for hypertrophic pyloric stenosis, although the reported data was from the mean operating time [14]. The study of Adibe et al. [16] showed an institutional learning curve when LP was introduced, as reflected by slightly higher rates of mucosal injury and incomplete pyloromyotomy.

Furthermore, a significant difference in median operating time and hospital stay was seen between the OP and LP patients, with a shorter hospital stay reported for the LP patients. The decline in complication rate seen for infants who underwent LP emphasizes the need for more followup assessment of these patients to determine whether this positive learning curve is maintained. Further research by means of a randomized clinical trial is needed to justify LP as the standard of care.

Introducing a new technique requires careful attention to the procedure and information toward the patient and his or her parents. In recent years, the use of minimally invasive surgical procedures has gained increased popularity, not only in pediatric surgery but also in adult surgery. These techniques usually are adopted before evidence of safety has been fully established. When a new technique is introduced, the surgeon finds him- or herself gaining proficiency and experience with suitable patients and preferably under the supervision of an experienced colleague. Hence, the surgeon embarks on a "learning curve" [17].

Over the past decade, LP has gained popularity with the advancement of laparoscopic technology and the development of instrumentation suitable for use with infants. Where a surgeon embarks on any learning curve, it is necessary to inform the patient of any uncertainty regarding risks and outcomes associated with the procedure and to ensure that the patient fully understands that the procedure is new.

The LP approach was introduced in our clinic by a surgeon trained in another hospital. All parents were informed about the novelty of the technique and offered a choice between two techniques. Informed consent was obtained as for every other procedure performed in our institution. Nevertheless, to avoid unnecessary harm to patients, it is important for surgeons to reflect on their own competence in performing any novel technique.

\section{Conclusion}

A significant decrease in the number and severity of complications was seen between the first and second groups of LP patients, indicating that the learning curve in our series for LP involved 35 procedures. 
Between the OP and LP patients, no difference in postoperative complications was observed, but a significant difference in median operating time and hospital stay was seen. Further research by means of a solid randomized clinical trial or a metaanalysis of the available randomized clinical trials is needed to justify LP as the standard of care.

Disclosures M. W. N. Oomen, L. T. Hoekstra, R. Bakx, and H. A. Heij have no conflicts of interest or financial ties to disclose.

Open Access This article is distributed under the terms of the Creative Commons Attribution Noncommercial License which permits any noncommercial use, distribution, and reproduction in any medium, provided the original author(s) and source are credited.

\section{References}

1. Grant GA, McAleer JJ (1984) Incidence of infantile hypertrophic pyloric stenosis. Lancet 1:1177

2. Everett KV, Capon F, Georgoula C, Chioza BA, Reece A, Jaswon M, Pierro A, Puri P, Gardiner RM, Chung EM (2008) Linkage of monogenic infantile hypertrophic pyloric stenosis to chromosome 16q24. Eur J Hum Genet 16:1151-1154

3. Ramstedt C (1912) Zur operation der angeborenen pylorus stenose. Med Klin 8:1702-1705

4. Tan KC, Bianchi A (1986) Circumumbilical incision for pyloromyotomy. Br J Surg 73:399

5. Alain JL, Grousseau D, Terrier G (1991) Extramucosal pyloromyotomy by laparoscopy. Surg Endosc 5:174-175

6. Fujimoto T, Lane GJ, Segawa O, Esaki S, Miyano T (1999) Laparoscopic extramucosal pyloromyotomy versus open pyloromyotomy for infantile hypertrophic pyloric stenosis: which is better? J Pediatr Surg 34:370-372

7. Downey EC Jr (1998) Laparoscopic pyloromyotomy. Semin Pediatr Surg 7:220-224

8. Sitsen E, Bax NM, van der Zee DC (1998) Is laparoscopic pyloromyotomy superior to open surgery? Surg Endosc 12:813-815

9. Greason KL, Thompson WR, Downey EC, Lo Sasso B (1995) Laparoscopic pyloromyotomy for infantile hypertrophic pyloric stenosis: report of 11 cases. J Pediatr Surg 30:1571-1574

10. Scorpio RJ, Tan HL, Hutson JM (1995) Pyloromyotomy: comparison between laparoscopic and open surgical techniques. J Laparoendosc Surg 5:81-84

11. St Peter SD, Ostlie DJ (2008) Pyloric stenosis: from a retrospective analysis to a prospective clinical trial: the impact on surgical outcomes. Curr Opin Pediatr 20:311-314

12. Leclair MD, Plattner V, Mirallie E, Lejus C, Nguyen JM, Podevin G, Heloury Y (2007) Laparoscopic pyloromyotomy for hypertrophic pyloric stenosis: a prospective, randomized controlled trial. J Pediatr Surg 42:692-698

13. St Peter SD, Holcomb GW III, Calkins CM, Murphy JP, Andrews WS, Sharp RJ, Snyder CL, Ostlie DJ (2006) Open versus laparoscopic pyloromyotomy for pyloric stenosis: a prospective, randomized trial. Ann Surg 244:363-370

14. Kramer WL, van der Bilt JD, Bax NM, van der Zee DC (2003) Hypertrophic pyloric stenosis in infants: laparoscopic pyloromyotomy. Ned Tijdschr Geneeskd 147:1646-1650

15. Kim SS, Lau ST, Lee SL, Waldhausen JH (2005) The learning curve associated with laparoscopic pyloromyotomy. J Laparoendosc Adv Surg Tech A 15:474-477

16. Adibe OO, Nichol PF, Flake AW, Mattei P (2006) Comparison of outcomes after laparoscopic and open pyloromyotomy at a highvolume pediatric teaching hospital. J Pediatr Surg 41:1676-1678

17. Healey P, Samanta J (2008) When does the "learning curve" of innovative interventions become questionable practice? Eur J Vasc Endovasc Surg 36:253-257 